\title{
OPTIMALISASI PENINGKATAN TEKNOLOGI DALAM PENGEMBANGAN NOTIFIKASI SIAKAD BERBASIS MOBILE DI SEKOLAH BALIKPAPAN
}

\author{
Aidil Saputra Kirsan, Vika Fitratunnany Insanittaqwa, dan Nursanti Novi Arisa \\ Institut Teknologi Kalimantan \\ E-mail: aidil@lecturer.itk.ac.id
}

\begin{abstract}
ABSTRAK. Sistem Informasi Akademik (SIAKAD) di sekolah merupakan hal yang fundamental, terutama bagi siswa dan orang tua. Namun penerapan sistem informasi pendidikan tersebut belum menjangkau semua lembaga pendidikan, misalnya SD Al-Azhar 58 di Balikpapan. SIAKAD di sekolah ini masih bersifat manual, sehingga orang tua atau wali harus datang langsung ke sekolah untuk memantau akademik siswa. Oleh karena itu, kami membangun aplikasi notifikasi SIAKAD berbasis Android dimana orang tua dan siswa dapat melihat informasi nilai dan keuangan siswa melalui aplikasi tanpa harus ke sekolah. Tujuan pengabdian ini membantu dalam pengelolaan data nilai dan keuangan siswa untuk SIAKAD di Sekolah Balikapapan dalam berbasis mobile. Dengan adanya aplikasi notifikasi ini diharapkan dapat mempermudah orang tua dan siswa untuk mendapatkan informasi pendidikan yang lebih akurat, efektif, dan efisien. Sehingga, memudahkan sekolah untuk mengelola informasi tentang perkembangan akademik siswa. Hasil pengabdian yang telah dilakukan yakni telah dirancang sebuah aplikasi SIAKAD berbasis mobile pada sekolah Al-Azhar 58 Balikpapan. Kemudian, pengujian kepada pihak sekolah yang telah dikembangkan sudah sesuai dengan kebutuhan.
\end{abstract}

Kata kunci: SIAKAD; Android: Notifikasi; Aplikasi

ABSTRACT. The academic information system (SIAKAD) in a school is fundamental, especially for students and parents. However, the implementation of the educational information system has not yet reached all educational institutions. For example, the Al-Azhar 58 elementary school in Balikpapan. The SIAKAD at the school is still manual, so parents or guardians must visit the school directly to monitor students' academic progress. Therefore, we built an Android-based educational notification application where parents and students can view information about students' grades and finances through the application without going to school. With this notification application, it is hoped that it will make it easier for parents and students to get more accurate, effective, and efficient educational information. Consequently, making it easier for schools to distribute information about students' intellectual development.

Keywords: SIAKAD; Android; Notification; Application

\section{PENDAHULUAN}

Saat ini, kita bisa menemukan sistem notifikasi di berbagai perangkat, seperti smartphone, smartwatch, atau tablet. Dengan adanya sistem notifikasi, berdampak pada efektifitas pekerjaan yang dapat diselesaikan oleh pengguna smartphone. Selain memberikan informasi penting, notifikasi juga berfungsi sebagai pengingat informasi yang telah, sedang, atau akan dilakukan oleh penerima. Biasanya pengguna smartphone akan menyempatkan diri untuk melihat atau membaca notifikasi di smartphone meskipun dalam kondisi sibuk. Hal ini dikarenakan sifat dari sistem notifikasi adalah respon yang cepat dalam menyampaikan informasi kepada pengguna (Triawan, 2021).

Penelitian (Susilawaty, 2021) yang terkait penggunaan sistem notifikasi telah dilakukan sejak lahirnya perangkat telepon genggam. Mulai dari Global System for Mobile Communications (GSM) atau Code Division Multiple Access (CDMA) hingga berbasis Internet Protocol (IP), atau secara singkat disebut Internet (Neeraja, 2017). Contoh sistem notifikasi sederhana berbasis GSM seperti voice call, short message service, dan multimedia messaging service. Untuk sistem notifikasi berbasis internet biasanya tergantung pada aplikasi di sistem operasi pada perangkat smartphone. Android dan iOS merupakan dua sistem operasi pada perangkat smartphone yang cukup mendominasi saat ini.

Telah banyak penelitian yang membahas tentang sistem notifikasi pada smartphone sebagai solusi dari berbagai permasalahan dalam kehidupan (Sanmorino, 2019) \& (Murata, 2021). Beberapa penelitian yang telah dilakukan antara lain sistem notifikasi bencana pintar yang memanfaatkan Short Message Service (SMS) atau voice call untuk menginformasikan rute optimal menuju tempat perlindungan terdekat (Satria, 2019), Kemudian, ada juga penelitian yang menggunakan push notification untuk pemilihan layanan koneksi nirkabel, berdasarkan layanan dan kecepatan akses (Triawan, 2021). Selain pemanfaatan, penelitian ini juga berfokus pada kinerja sistem, dengan pengujian dan analisis push notification yang digunakan (Okoshi, 2019). Melalui penelitian ini, kami mencoba mengusulkan rancangan sistem notifikasi pintar yang berjalan pada sistem operasi Android. Notifikasi pintar ini akan digunakan untuk pengumuman nilai dan pembayaran pada sistem akademik (SIAKAD) di lingkungan sekolah di Balikpapan.

Sistem pengumuman saat ini hanya bergantung pada portal web, telepon, grup di media sosial atau sistem pesan singkat. Penggunaan portal web dan 
telepon masih memiliki banyak keterbatasan. Hal inilah yang melatarbelakangi kami untuk membuat notifikasi pintar yang berjalan di sistem operasi Android. Pada prinsipnya cara kerja sistem notifikasi memiliki kemiripan dengan sistem informasi pada umumnya, yang bertujuan untuk memberikan informasi kepada pengguna. Yang membedakannya, jika sistem informasinya sedikit pasif, maka sistem notifikasinya aktif dan sangat dinamis. Aspek lain yang perlu diperhatikan adalah masalah keamanan, dengan penggunaan sistem notifikasi berbasis Android diharapkan dapat mengurangi pencurian dan penyalahgunaan data.

Permasalahan Sekolah Al-Azhar 58 Balikpapan belum menerapkan SIAKAD dikarenakan kurangnya tenaga pengajar IT yang berada di sekolah tersebut sehingga kami membangun sistem peningkatan teknologi dalam pengembangan notifikasi siakad berbasis mobile. Menurut Kepala Sekolah Al-Azhar 58 Balikpapan, upaya dari pihak lain untuk sekolah ini dalam membangun SIAKAD berbasis mobile masih hanya sebatas ide pada tahun 2019 dan sampai sekarang masih belum terealisasikan.

\section{METODE}

Metode pengabdian adalah langkah-langkah yang diperlukan untuk melaksanakan pengabdian dari dimulai sampai pengabdian selesai. Metode yang kami gunakan dalam pengabdian ini adalah sebagai berikut Gambar 1.

\section{Studi Literatur dan Pemahaman Konsep: Pada} tahap ini kami melakukan studi literatur, membaca penelitian terkait dan publikasi yang telah dilakukan oleh peneliti lain. Dengan membaca penelitian terkait yang telah dilakukan sebelumnya, akan menambah pengetahuan dan pemahaman tentang konsep sistem notifikasi akademik yang akan dikembangkan.

2. Perbaikan, Desain dan Analisis, Kebutuhan Sistem: Pada tahap ini, berdasarkan pemahaman yang telah diperoleh dari tahap sebelumnya, kami mencoba mencari peluang untuk memperbaiki pengabdian yang sudah ada sebelumnya terkait. Disini kami juga mencoba memperbaiki kekurangan dan keterbatasan dalam perancangan sistem notifikasi dari penelitian sebelumnya. Kemudian dilanjutkan dengan perancangan untuk mendapatkan konsep awal sistem notifikasi yang akan dikembangkan. Analisis dilakukan untuk mengetahui faktor-faktor yang mempengaruhi desain yang telah dibuat. Dari hasil analisa juga diketahui berbagai kekurangan dan apa yang ditambahkan agar sesuai dengan kebutuhan.

3. Pengembangan Sistem: Dari hasil analisis diketahui kebutuhan dan spesifikasi sistem notifikasi yang akan dikembangkan. Terutama hal-hal yang berkaitan dengan data dan informasi yang akan disimpan dalam basis data.

4. Persyaratan dan Basis Data: Tahap selanjutnya adalah mengembangkan sistem notifikasi berdasarkan desain dan kebutuhan database yang telah dilakukan pada tahap sebelumnya. Tahap ini melibatkan desainer, programmer, dan analis untuk saling berkomunikasi sehingga sistem yang dikembangkan sesuai dengan kebutuhan. Skema basis data untuk sistem akademik dapat dilihat pada Gambar 2.

Database untuk sistem notifikasi terdiri dari 8 tabel, yaitu:

1. dsq keuangan. Digunakan untuk menyimpan informasi keuangan (kelompok keuangan, nama keuangan, deskripsi dan urutan).

2. dsq kelompok_keuangan. Digunakan untuk menyim-pan informasi kelompok keuangan (nama kelompok keuangan, deskripsi, dan urutan).

3. dsq nilai. Digunakan untuk menyimpan informasi nilai (kelompok nilai, nama nilai, deskripsi dan urutan).

4. dsq_kelompok_nilai. Digunakan untuk menyimpan informasi kelompok nilai (nama kelompok nilai, deskripsi, dan urutan).

5. dsq_keuangan_santri. Digunakan untuk menyimpan
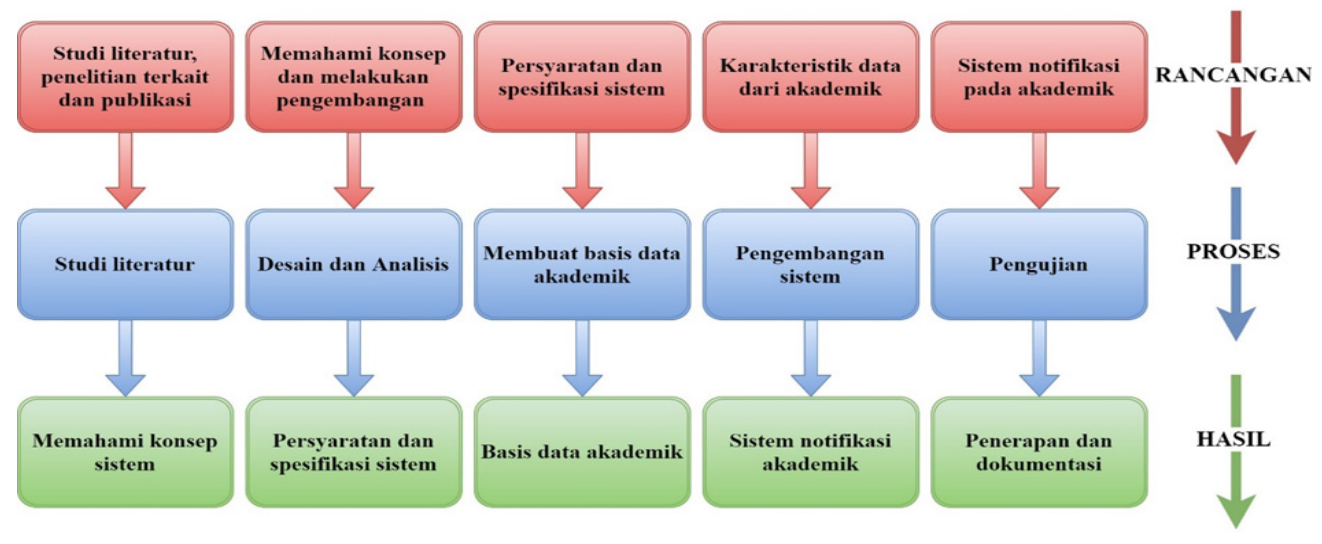

Gambar 1. Metode untuk Mengembangkan Sistem Akademik

Optimalisasi Peningkatan Teknologi dalam Pengembangan Notifikasi Siakad Berbasis Mobile di Sekolah Balikpapan (Aidil Saputra Kirsan, Vika Fitratunnany Insanittaqwa, dan Nursanti Novi Arisa) 
informasi keuangan santri (penempatan, keuangan, tanggal bayar dan tanggal tempo).

6. dsq penempatan. Digunakan untuk menyimpan informasi penempatan (sesi, jenjang, kelas dan santri).

7. dsq nilai santri. Digunakan untuk menyimpan informasi nilai santri (penempatan, nama nilai, dan nilai).

8. dsq santri. Digunakan untuk menyimpan informasi santri (nama, nisn, email, tanggal lahir, jenis kelamin, alamat, telpon, hobi, password, angkatan dan foto).

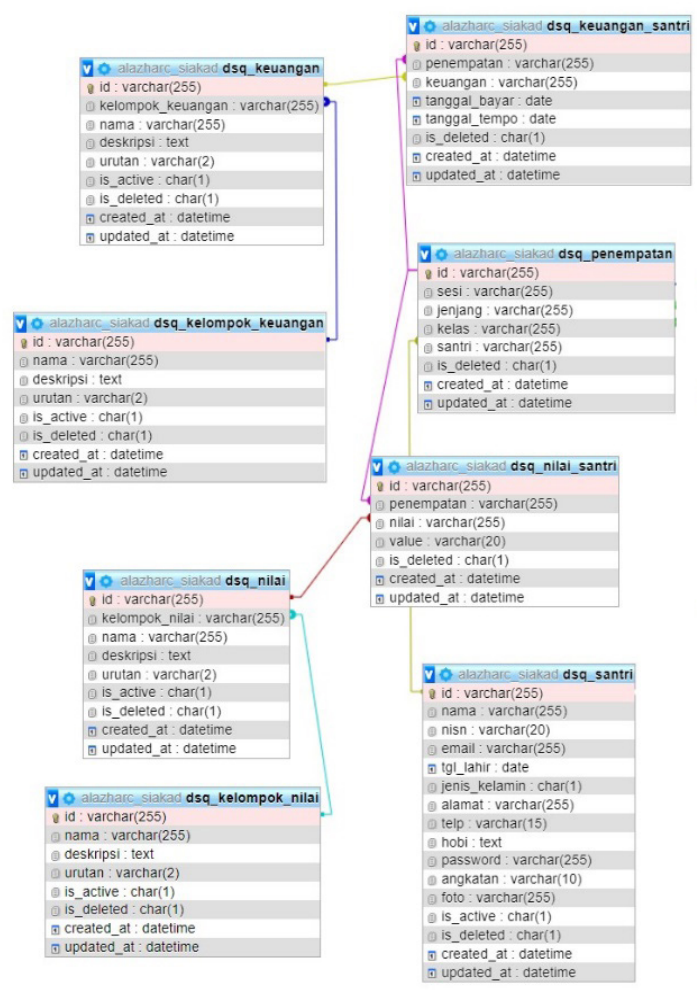

Gambar 2. Skema Basis Data Sistem Notifikasi

5. Pengujian, Penerapan dan Dokumentasi: Perbandingan lebih lanjut dari sistem notifikasi kinerja telah dikembangkan dengan hasil pengabdian identik yang telah dilakukan sebelumnya. Perbandingan kinerja dilakukan denganmengujisistem notifikasi. Halini dilakukan untuk mengetahui seberapa baik kinerja sistem notifikasi yang telah dikembangkan. Setelah mengetahui kinerja sistem, tahapan yang tidak kalah pentingnya adalah membuat dokumentasi rangkaian proses yang telah dilakukan dilanjutkan dengan dokumentasi fungsi sistem notifikasi yang telah dikembangkan. Karena pengabdian ini masih berlangsung, maka pengabdian kami hanya sampai pada tahap desain, analisis, dan penerapan.

Penerapan yang telah dihasilkan kepada pihak sekolah yakni pelaksanaan workshop dan serah terima aplikasi kepada pihak kepala sekolah Al-Azhar 58 Balikpapan

\section{HASIL DAN PEMBAHASAN}

Pada bab ini adalah kegiatan mengimplementasikan dan menguji sistem. Bab ini berisi tentang implementasi aplikasi sistem akademik khususnya notifikasi nilai dan keuangan santri yang dirujuk berdasarkan hasil analisis dan desain yang dijelaskan pada bab sebelumnya. Berikut hasil desain untuk sistemnya:

\section{Halaman Login:}
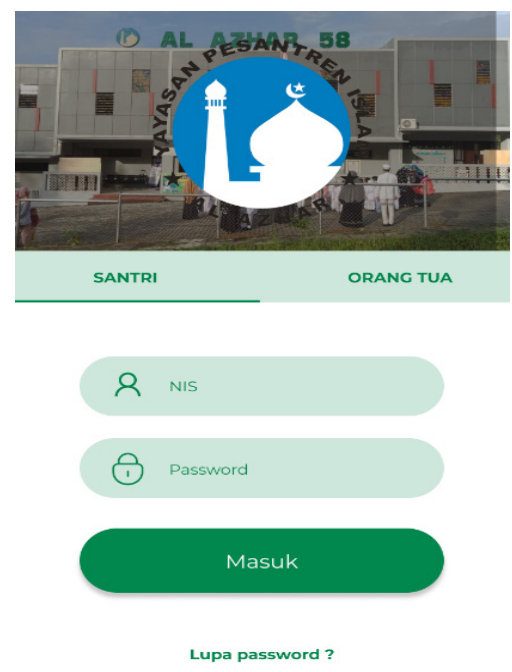

DSQ Apps vi.o

Gambar 3. Halaman Login

Pada gambar 3 di atas merupakan halaman login dimana halaman hak akses bagi santri berfungsi untuk melihat notifikasi data pada sistem. Jika santri ingin masuk ke halaman selanjutnya maka santri hendak memasukkan NIS dan passwordnya terlebih dahulu. Apabila santri lupa dengan passwordnya maka terdapat pula fungsi tombol 'Lupa Password' pada bagian bawah.

\section{Halaman Nilai:}

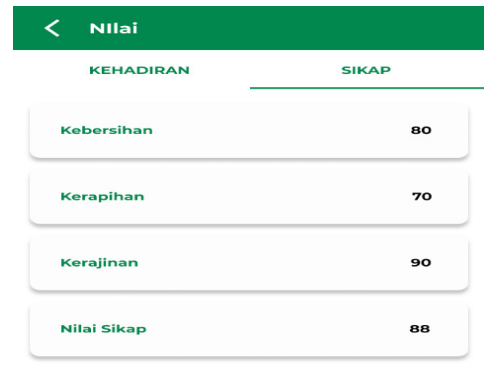

\section{Gambar 4. Halaman Nilai}

Pada gambar 4 di atas merupakan halaman nilai santri. Kita bisa melihat ada dua kelompok nama penilaian yang diberikan seperti kehadiran dan sikap. Di dalam sikap, ada beberapa jenis penilaiannya seperti kebersihan, kerapihan, kerajinan, dan nilai sikap beserta nilainya masing-masing. Sehingga setiap santri bisa melihat nilainya dengan jelas dan transparan di smartphonenya tanpa harus datang ke sekolah. 


\section{Halaman Keuangan:}

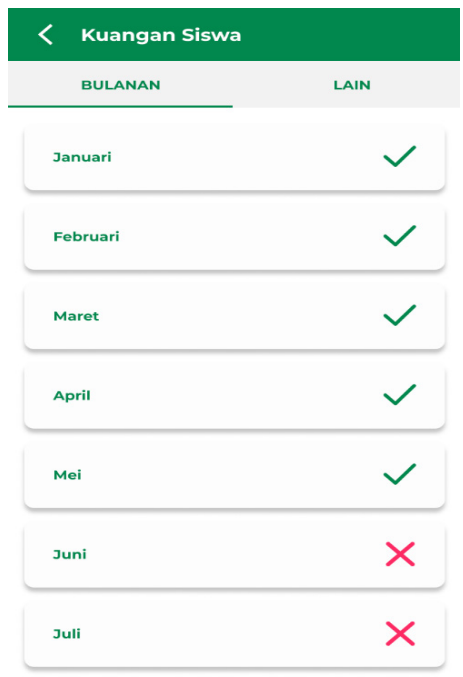

Gambar 5. Halaman Keuangan

Pada gambar 5 di atas merupakan halaman keuangan santri. Kita bisa melihat ada dua kelompok nama keuangan yang diberikan seperti bulanan dan lain. Di dalam halaman bulanan, ada beberapa jenis nama yang tertera seperti Januari hingga Juli beserta tandanya. Sehingga setiap santri bisa melihat keuangan yang mana saja belum terbayarkan pada bulan tertentu tanpa harus menanyakan ke guru atau staf di sekolahnya.

Pada tahap penerapan ini, kami mengadakan sebuah demonstrasi dan workshop aplikasi SIAKAD berbasi mobile. Kami mengadakan workshop terhadap kepala sekolah dan salah satu guru sebagai inputan data siswa yang akan diimplementasikan pada android. Setelah melakukan workshop, peneliti menjaring tingkat kepuasan pengguna dengan melakukan pengujian yang bertujuan untuk mengetahui apakah fitur aplikasi yang telah dikembangkan sudah sesuai dengan kebutuhan. Hasil dari pengujian ini dapat dilihat pada tabel 1.

Tabel 1. Hasil Uji Aplikasi

\begin{tabular}{lllcl}
\hline No & \multicolumn{1}{c}{ Fitur } & \multicolumn{1}{c}{ Ekspektasi } & Hasil & Keterangan \\
\hline 1 & Lihat Data & Data Siswa dapat & Terlihat & Sesuai \\
& Siswa & Terlihat & & \\
2 & Lihat Nilai & Nilai Siswa dapat & Terlihat & Sesuai \\
& Siswa & Terlihat & & \\
3 & Lihat Pembayar- & Pembayaran & Terlihat & Sesuai \\
& an Keuangan & Keuangan dapat & & \\
& Siswa & Terlihat & & \\
\hline
\end{tabular}

Dari hasil tabel 1, ekspektasi dari pihak sekolah telah dilaksanakan sesuai harapan dari pihak sekolah. Maka dari ituketiga fitur diatas telah selesai dikerjakan dan sesuai. Setelah hasil uji aplikasi selesai maka dilakukan serahterima aplikasi kepada pihak kepala sekolah. Berikut gambar 6 hasil kegiatan workshop dan serah terima pada tanggal 22 September 2021 di Sekolah Al-Azhar 58 Balikpapan.
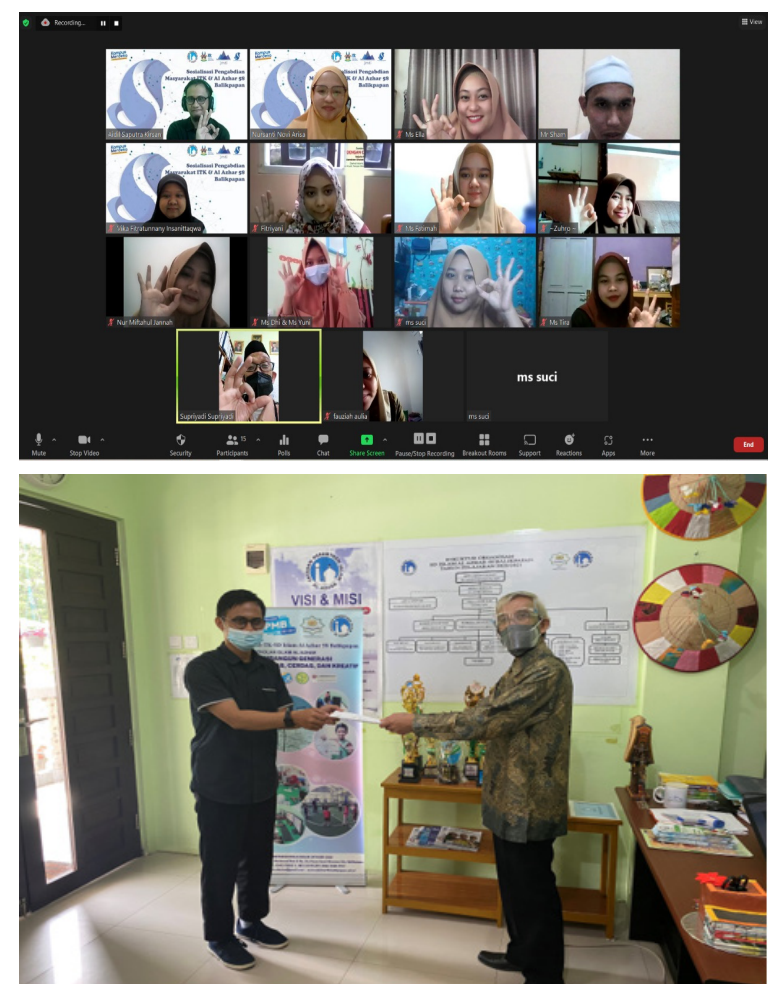

Gambar 6. Hasil Kegiatan dan Serah terima

\section{SIMPULAN}

Berdasarkan hasil kegiatan pengabdian masyarakat optimalisasi peningkatan teknologi dalam pengembangan notifikasi SIAKAD berbasis mobile di sekolah balikpapan, dapat disimpulkan bahwa siswa dapat masuk ke halaman login untuk melihat notifikasi data akademik. Kemudian, siswa juga dapat melihat informasi nilai dan keuangan melalui smarthphone berbasi mobile. Dengan demikian, Sistem Informasi Akademik berbasis mobile telah berhasil diimplementasi di Sekolah Al-Azhar 58 di Balikpapan. Dari hasil pengujian aplikasi respon para pengguna baik guru, siswa, dan kepala sekolah sudah sesuai hasil yang diharapkan.

\section{UCAPAN TERIMAKASIH}

Institut Teknologi Kalimantan mendukung pengabdian ini di bawah LPPM-nya. Para peneliti berterima kasih atas dukungan ini. Peneliti juga mengucapkan terima kasih kepada Sekolah Al-Azhar 58 Kota Balikpapan yang telah menyediakan datanya. Kami juga ingin menyampaikan penghargaan kami kepada semua teman kami yang membantu kami secara langsung dan tidak langsung.

\section{DAFTAR PUSTAKA}

Murata, K. 2021. CHIAPON: An Anthropomorphic Character Notification System that Discourages Their Excessive Smartphone Use. In International Conference on Human-Computer Interaction (pp. 432-445). Springer, Cham. 
Neeraja, S., \& Rao, G. S. 2017. A Comparative Study on Handoff Algorithms for GSM and CDMA Cellular Networks. International Journal of Electrical \& Computer Engineering (20888708), 7(3).

Okoshi, T., Tsubouchi, K., \& Tokuda, H. 2019. Real-world product deployment of adaptive push notification scheduling on smartphones. In Proceedings of the 25th ACM SIGKDD International Conference on Knowledge Discovery \& Data Mining (pp. 2792-2800).

Sanmorino, A., Fajri, R. M., Hamim, S. A., Afriyani, F., Gustriansyah, R., Suhandi, N., ... \& Hildayanti, S. K. 2019. E-announcement as an early warning notification using smartphone devices in a college. In Journal of Physics: Conference Series (Vol. 1153, No. 1, p. 012030). IOP Publishing.
Satria, D., Zulfan, Z., Munawir, M., \& Mulyati, D. 2019. Final Project Consultation Information System Integrated Notification System Based on Sms Gateway. Cyberspace: Jurnal Pendidikan Teknologi Informasi, 2(2), 135140.).

Susilawaty, S. 2021. Aplikasi monitoring perkuliahan dengan notifikasi menggunakan short massage service (sms) gateway pada akademik kebidanan banjarbaru (Doctoral dissertation, Univesitas Islam Kalimantan MAB).

Triawan, A., \& Alipudin, W. 2021. Penerapan Representational State Transfer (REST) Pada Push Notification Whatsapp Untuk Layanan Informasi Akademik. Teknois: Jurnal Ilmiah Teknologi Informasi dan Sains, 11(1), 59-66. 